\title{
Idiopathic pulmonary fibrosis and p-ANCA positivity predating manifestations of systemic vasculitis
}

\author{
Kashif Ali Khan ${ }^{1 *}$, Deirdre Fitzgerald ${ }^{1}$, Mike Harrison ${ }^{1}$, Michael M. Maher ${ }^{2}$, Michael T. Henry ${ }^{1}$, Marcus P. Kennedy ${ }^{1}$, Barry J. Plant ${ }^{1}$ and \\ Desmond Murphy'
}

*Correspondence: drkhan95@hotmail.com

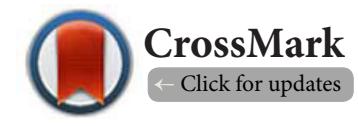

'Department of Respiratory Medicine, Cork University Hospital, University College Cork, Ireland.

${ }^{2}$ Department of Radiology, Cork University Hospital, University College Cork, Ireland.

\begin{abstract}
The occurrence of perinuclear anti-neutrophilic cytoplasmic antibodies (p-ANCA) in pulmonary fibrosis has been reported in a number of small studies, however, the appearance of p-ANCA in already established idiopathic pulmonary fibrosis (IPF), predating the manifestations of vasculitis has not been widely appreciated. We report 2 cases with radiographic evidence of established IPF where p-ANCA was negative at the time of diagnosis and became positive during the course of the disease, for a variable period of time, prior to the subsequent development of systemic vasculitis. Our cases suggest a possible rationale for serial p-ANCA measurements in patients with pulmonary fibrosis even in the absence of features suggestive of vasculitis. Furthermore, the required frequency of ANCA measurement in the absence of clinical features of vasculitis is unknown. Larger studies with repetitive p-ANCA measurement in tandem with ongoing clinical assessment for vasculitis are required to assess the prevalence of ANCA and to confirm our observation.
\end{abstract}

Keywords: Pulmonary fibrosis, vasculitis, ANCA, microscopic polyangiitis

\section{Introduction}

Anti neutrophilic cytoplasmic antibodies (ANCA) are directed against enzymes in the granules of polymorphonuclear leukocytes. ANCA positivity has been associated with vasculitides with the potential for pulmonary involvement. Cytoplasmic anti-neutrophilic cytoplasmic antibodies (c-ANCA) has high sensitivity and specificity for patients with granulomatosis with polyangiitis, whereas, perinuclear anti-neutrophilic cytoplasmic antibodies ( $p-A N C A$ ) is characteristically associated with small vessel vasculitis (mainly-Churg-Strauss syndrome, pauci-immune glomerulonephritis and microscopic polyangiitis). ANCA is therefore an important serological biomarker for diagnosing and monitoring systemic vasculitis.

The occurrence of $p$-ANCA in pulmonary fibrosis has been reported in a number of small studies $[1,2]$, however, the appearance of $\mathrm{p}$-ANCA in already established idiopathic pulmonary fibrosis (IPF), predating the manifestations of vasculitis has not been widely appreciated [2]. We report 2 cases with radiographic evidence of established IPF where p-ANCA was negative at the time of diagnosis and became positive prior to the subsequent development of systemic vasculitis.

\section{Short report}

Case 1

A 70 year old non-smoking, female, presented with progressive breathlessness on exertion and bi-basal crackles on chest auscultation. A high resolution computed tomography of thorax (Figure 1) demonstrated the changes consistent with usual interstitial pneumonia (UIP). Pulmonary function testing demonstrated a pattern consistent with restrictive lung disease Table 1. Her p-ANCA was negative at the time of diagnosis (Figure 2). Her IPF remained stable radiologically; however there was a gradual decline in DLCO to $44 \%$ predicted at 3 years. At this time, p-ANCA was noted to be positive and remained positive until two years later when her MPO titres suddenly increased and were associated with the development of mononeuritis, manifesting as right foot drop and stage 3 renal diseases. These manifestations, together with $\mathrm{p}$-ANCA positivity were consistent with systemic vasculitis. The clinical and laboratory findings are suggestive of microscopic polyangiitis. Her TLC at this time was $68 \%$ predicted with a DLCO of $38 \%$ predicted. She was commenced on immunosuppressive treatment (cyclophosphamide and steroids) which resulted in improvement in foot drop, stabilization 

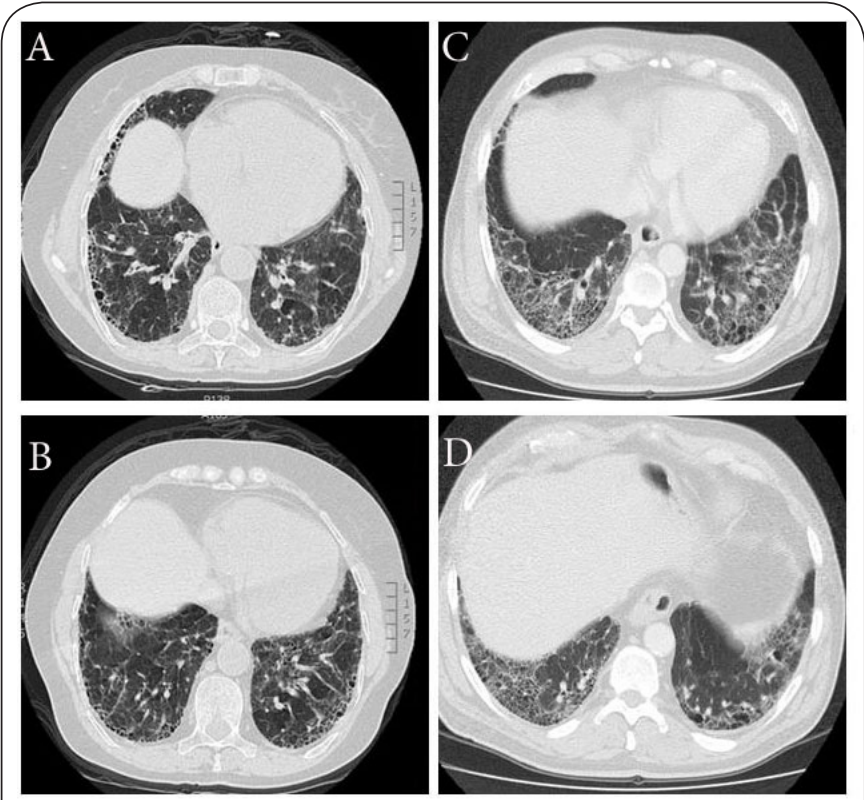

Figure 1. Axial high resolution computerized tomography of the case 1 (A and $\mathbf{B}$ ) and case $2(\mathbf{C}$ and $\mathbf{D})$ showing peripheral subpleural honeycomb cyst formation symmetrically at both lung bases. More centrally there is groundglass opacification suggesting fine fibrosis and some architectural distortion. Findings are consistent with usual interstitial pneumonia (UIP).

Table 1. Pulmonary function testing.

\begin{tabular}{lllll}
\hline & $\mathbf{2 0 0 7}$ & $\mathbf{1 0 / 2 0 1 1}$ & $\mathbf{0 7 / 2 0 1 2}$ & $\mathbf{0 1 / 2 0 1 3}$ \\
\hline FEV1 & $1.97(95 \%)$ & $1.39(88 \%)$ & $1.33(80.5 \%)$ & $1.07(69 \%)$ \\
FVC & $1.97(81 \%)$ & $1.77(91 \%)$ & $1.60(82.7 \%)$ & $1.30(70 \%)$ \\
FEV1/FVC & $82 \%$ & $82.7 \%$ & $78.8 \%$ & $79 \%$ \\
TLC & $73 \%$ & -- & $67.8 \%$ & $63.6 \%$ \\
DLCO & $94 \%$ & $43.5 \%$ & $37.5 \%$ & $32.8 \%$ \\
\hline
\end{tabular}

FEV1: Forced expiratory volume in one second $\%$ : Percentage predicted; FVC: Forced vital capacity TLC: Total lung capacity

DLCO: Diffusion capacity for carbon monoxide

of renal profile and a reduction in measured MPO titres. She remains clinically stable and subsequently maintained on azathioprine and low dose steroids.

\section{Case 2}

Our second case, a 64 year old, male, ex-smoker of 18 years (40 pack year history), initially presented to another institution with a two month history of breathlessness on exertion. Auscultation of his chest revealed bi-basal crackles. A diagnosis of IPF with UIP pattern was made based on radiology (Figures 1C and 1D) and consistent lung function testing. His TLC at this time was $77 \%$ predicted with a DLCO of $53 \%$ predicted. His p-ANCA at the time of diagnosis was negative. Two years later, he was referred for lung transplant assessment and was noted to be
p-ANCA positive. He remained p-ANCA positive and twelve months later his MPO titres rose with subsequent development of haemoptysis and acute respiratory and renal failure (Figure 3).

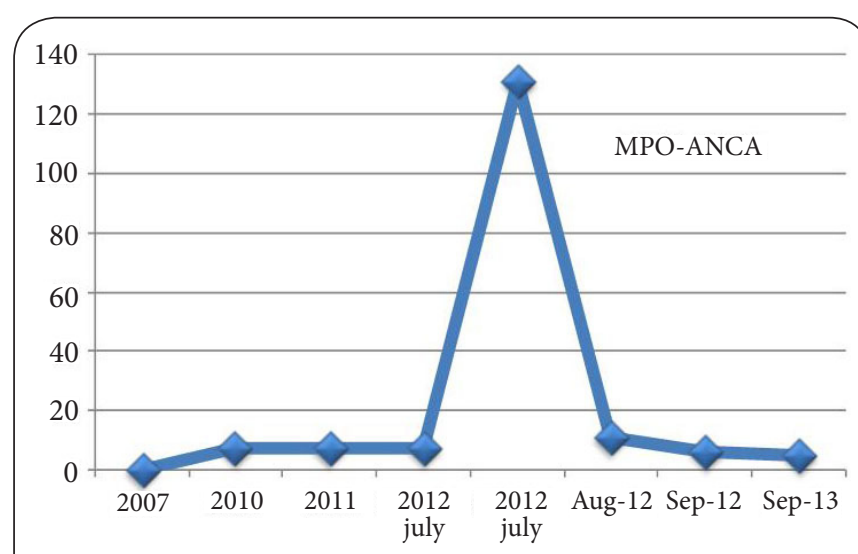

Figure 2. MPO-ANCA titres during the course of the disease. There was sudden rise with characteristic manifestations of systemic vasculitis and subsequent stabilization with immunosuppressant treatment.

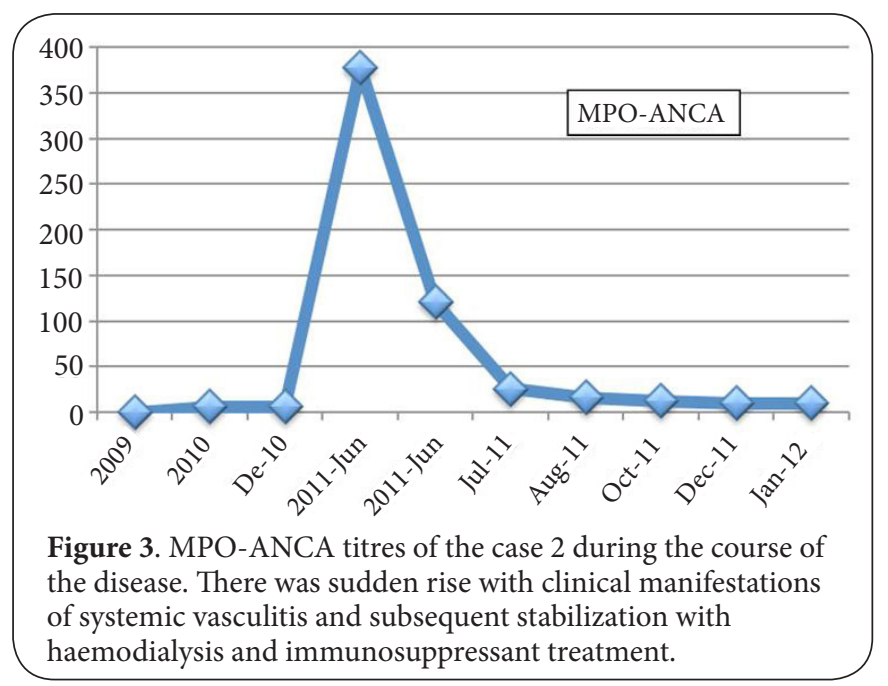

He was managed with plasma exchange, haemodialysis and immunosuppressant treatment. There was slow improvement in the patient's clinical status with co-existent radiological improvement observed on serial chest $x$-rays. His MPO titres also decreased in response to therapy. He remained on stable on immunosuppressant therapy (cyclophosphamide and steroids), and haemodialysis for one year but unfortunately suffered a fatal cardiac arrhythmia while an inpatient for the management of a fracture.

\section{Discussion}

The temporal relationship between $p$-ANCA positivity in already established pulmonary fibrosis and the development of vasculitis is poorly understood. Here, we report two cases 
in which p-ANCA was negative at the time of diagnosis of pulmonary fibrosis and became positive during follow-up, predating the onset of fulminant vasculitis. There are no reported differences in the clinical or radio graphical characteristics of $p$-ANCA positive as compared to $p$-ANCA negative pulmonary fibrosis at the time of initial diagnosis [3]. However, in the presence of p-ANCA positivity, the clinical course of the disease may be affected, with increased morbidity and mortality observed $[3,4]$. In our report there was lack of histological confirmation, however, diagnosis of microscopic polyangitis was made clinically in combination with positive MPO-ANCA testing [5].

The exact pathophysiological mechanism of the relationship between ANCA and pulmonary fibrosis remains undetermined. The predominant histological and radiological pattern for pulmonary fibrosis that has been reported in such cases is UIP [6]. Early histological studies did not detect marked differences in the degree of lung fibrosis among various types of vasculitis, suggesting that ANCA may cause a generalized type of tissue injury, possibly through the release of activated neutrophils. In one report, cumulative cigarette smoking tended to be higher in ANCA-positive patients with pulmonary fibrosis than in ANCA-negative cases [2]. Cigarette smoke has the potential to induce activated neutrophilic infiltration into the lung tissues [7]. Increased MPO on activated neutrophils promote degranulation and oxidative bursts that could lead to alveolar epithelial damage, fibroblastic proliferation and ultimately the development of fibrosis [8]. Another conceivable mechanism is that at early stages of the disease, ANCA levels remain below the threshold of conventional laboratory measurements and once the levels rise and become detectable by laboratory methods, the disease manifest itself clinically, with features of vasculitis [9]. However the reason for this remains beyond cogitation and may be related to unidentified infectious or noninfectious antigens, autoimmunity, impaired regenerative responses, and the antagonistically pleiotropic action of genes involved in wound healing or development $[10,11]$.

Our cases suggest a possible rationale for serial p-ANCA measurements in patients with pulmonary fibrosis even in the absence of features suggestive of vasculitis. International IPF guidelines place high value on measuring autoimmune serology to distinguish IPF from pulmonary disease associated with connective tissue disease. However, the routine use of extended serological testing, in particular ANCA measurement has not been emphasized [12]. Furthermore, the required frequency of ANCA measurement in the absence of clinical features of vasculitis is unknown. Larger studies with repetitive $p$-ANCA measurement in tandem with ongoing clinical assessment for vasculitis are required to confirm or refute our observations.

\section{Competing interests}

The authors declare that they have no competing interests.
Authors' contributions

\begin{tabular}{|l|c|c|c|c|c|c|c|c|}
\hline Authors' contributions & KK & DF & MH & MMM & MTH & MPK & BJP & DM \\
\hline $\begin{array}{l}\text { Research concept and } \\
\text { design }\end{array}$ & $\checkmark$ & -- & -- & -- & -- & -- & -- & $\checkmark$ \\
\hline $\begin{array}{l}\text { Collection and/or } \\
\text { assembly of data }\end{array}$ & $\checkmark$ & -- & -- & -- & -- & -- & -- & -- \\
\hline $\begin{array}{l}\text { Data analysis and } \\
\text { interpretation }\end{array}$ & $\checkmark$ & -- & -- & -- & -- & -- & -- & $\checkmark$ \\
\hline Writing the article & $\checkmark$ & -- & -- & -- & -- & -- & -- & $\checkmark$ \\
\hline $\begin{array}{l}\text { Critical revision of the } \\
\text { article }\end{array}$ & $\checkmark$ & -- & -- & $\checkmark$ & -- & $\checkmark$ & -- & $\checkmark$ \\
\hline Final approval of article & $\checkmark$ & $\checkmark$ & $\checkmark$ & $\checkmark$ & $\checkmark$ & $\checkmark$ & $\checkmark$ & $\checkmark$ \\
\hline Statistical analysis & $\checkmark$ & -- & -- & -- & -- & -- & -- & $\checkmark$ \\
\hline
\end{tabular}

Publication history

EIC: Victor J. Thannickal, University of Alabama at Birmingham, USA. Received: 26-Sep-2014 Final Revised: 06-Dec-2014

Accepted: 09-Jan-2015 Published: 23-Jan-2015

\section{References}

1. Hervier B, Pagnoux C, Agard C, Haroche J, Amoura Z, Guillevin L and Hamidou MA. Pulmonary fibrosis associated with ANCA-positive vasculitides. Retrospective study of 12 cases and review of the literature. Ann Rheum Dis. 2009; 68:404-7. I Article I PubMed

2. Foulon G, Delaval P, Valeyre D, Wallaert B, Debray MP, Brauner M, Nicaise P, Cadranel J, Cottin V, Tazi A, Aubier M and Crestani B. ANCA-associated lung fibrosis: analysis of 17 patients. Respir Med. 2008; 102:1392-8. | Article I PubMed

3. Nozu T, Kondo M, Suzuki K, Tamaoki J and Nagai A. A comparison of the clinical features of ANCA-positive and ANCA-negative idiopathic pulmonary fibrosis patients. Respiration. 2009; 77:407-15. | Article | PubMed

4. Tzelepis GE, Kokosi M, Tzioufas A, Toya SP, Boki KA, Zormpala A and Moutsopoulos HM. Prevalence and outcome of pulmonary fibrosis in microscopic polyangiitis. Eur Respir J. 2010; 36:116-21. I Article I PubMed

5. Watts R, Lane S, Hanslik T, Hauser T, Hellmich B, Koldingsnes W, Mahr A, Segelmark M, Cohen-Tervaert JW and Scott D. Development and validation of a consensus methodology for the classification of the ANCA-associated vasculitides and polyarteritis nodosa for epidemiological studies. Ann Rheum Dis. 2007; 66:222-7. | Article | PubMed Abstract | PubMed Full Text

6. Homma S, Matsushita H and Nakata K. Pulmonary fibrosis in myeloperoxidase antineutrophil cytoplasmic antibody-associated vasculitides. Respirology. 2004; 9:190-6. I Article I PubMed

7. Churg A, Zay K, Shay S, Xie C, Shapiro SD, Hendricks R and Wright JL. Acute cigarette smoke-induced connective tissue breakdown requires both neutrophils and macrophage metalloelastase in mice. Am J Respir Cell Mol Biol. 2002; 27:368-74. | Article I PubMed

8. Guilpain P, Chereau C, Goulvestre C, Servettaz A, Montani D, Tamas N, Pagnoux C, Hachulla E, Weill B, Guillevin L, Mouthon L and Batteux F. The oxidation induced by antimyeloperoxidase antibodies triggers fibrosis in microscopic polyangiitis. Eur Respir J. 2011; 37:1503-13. | Article | PubMed

9. Tzouvelekis A, Zacharis G, Oikonomou A, Koulelidis A, Steiropoulos P, Froudarakis M, Kriki $P$, Vargemezis $V$ and Bouros D. Combined pulmonary fibrosis and emphysema associated with microscopic polyangiitis. Eur Respir J. 2012; 40:505-7. | Article | PubMed

10. Thannickal VJ, Zhou Y, Gaggar A and Duncan SR. Fibrosis: ultimate and proximate causes. J Clin Invest. 2014; 124:4673-7. I Article I PubMed

11. Duncan SR. What is autoimmunity and why is it likely to be important in 
Khan et al. Pulmonology \& Respiratory Research 2015,

http://www.hoajonline.com/journals/pdf/2053-6739-3-1.pdf

chronic lung disease? Am J Respir Crit Care Med. 2010; 181:4-5. | Article I PubMed

12. Raghu G, Collard HR, Egan JJ, Martinez FJ, Behr J, Brown KK, Colby TV, Cordier JF, Flaherty KR, Lasky JA et al. An official ATS/ERS/JRS/ALAT statement: idiopathic pulmonary fibrosis: evidence-based guidelines for diagnosis and management. Am J Respir Crit Care Med. 2011; 183:788824. | Article | PubMed

\section{Citation:}

Khan KA, Fitzgerald D, Harrison M, Maher MM, Henry MT, Kennedy MP, Plant BJ and Murphy D. Idiopathic pulmonary fibrosis and $\mathbf{p}$-ANCA positivity predating manifestations of systemic vasculitis. Pulmonol Respir Res. 2015; 3:1.

http://dx.doi.org/10.7243/2053-6739-3-1 